\title{
Meteor observations with an MF radar
}

\author{
Masaki Tsutsumi ${ }^{1}$, David Holdsworth ${ }^{2}$, Takuji Nakamura ${ }^{3}$, and Iain Reid ${ }^{4}$ \\ ${ }^{1}$ National Institute of Polar Research, Tokyo, Japan \\ ${ }^{2}$ Atmospheric Radar Systems, Adelaide, Australia \\ ${ }^{3}$ Radio Atmospheric Science Center, Kyoto University, Uji, Kyoto, Japan \\ ${ }^{4}$ University of Adelaide, Adelaide, Australia
}

(Received August 19, 1998; Revised June 6, 1999; Accepted June 10, 1999)

\begin{abstract}
We conducted meteor echo observations using the Buckland Park MF radar $\left(35^{\circ} \mathrm{S}, 138^{\circ} \mathrm{E}\right)$ at 00:40-05:45 LT on October 22, 1997. In addition to the usual full correlation analysis (FCA) technique to measure horizontal wind velocities from 60 to $100 \mathrm{~km}$ MF radars have a potential to detect meteor echoes and infer winds through their Doppler frequency shifts. Because of the relatively low radio frequency employed MF radars have a great advantage of providing meteor wind well above $100 \mathrm{~km}$ altitude, where very few techniques can measure wind velocities. There is a limitation which should be noted as well. The observations are possible only during night time when the electron density of E-region is low enough for the radio wave to penetrate into the upper region. We detected 233 underdense meteor echoes from $80 \mathrm{~km}$ to $120 \mathrm{~km}$ with a mean height of $104.4 \mathrm{~km}$. Although the transmitting antenna beams were steered toward off-zenith angles of $25^{\circ}$, almost all the echoes were received outside of the main lobe, indicating that conventional MF radar systems with a broad transmitting beam can work well for meteor observations. Bi-hourly wind profiles were obtained from 94 to $114 \mathrm{~km}$ altitudes. The profiles revealed a clear wave structure with a downward phase progression with time. FCA winds from 80 to $100 \mathrm{~km}$ were also estimated, and a continuous wind structure was obtained from FCA to meteor heights. Note that the present observations happened to be conducted during a major meteor shower activity. However, a majority of the underdense echoes were from non-shower meteors, and observations during non-shower periods will also yield enough information.
\end{abstract}

\section{Introduction}

Wind measurement with MF radars is one of the most powerful techniques for studying the mesosphere and the lower thermosphere. It has greatly contributed to the study of atmospheric dynamics for three decades (e.g., Vincent, 1984). The technique usually utilizes partial reflection from weakly ionized atmospheric layers. A full correlation analysis (FCA) is mainly used to extract wind information from the data. The measurement can be performed with a time resolution as high as 2 min continuously throughout a day in $80-100 \mathrm{~km}$ altitude, and has provided wind data useful for the study of both short and long period atmospheric motions, from gravity waves to mean winds. Depending on the transmitting frequency employed, the observations are limited to altitudes below where the total reflection occurs. For conventional MF radar systems, which are operated at 2-3 $\mathrm{MHz}$, total reflection occurs around $100 \mathrm{~km}$ during day time. In addition the underlying assumption for the FCA is not necessarily thought to hold above $100 \mathrm{~km}$. Because of these reason the MF radar wind measurements have been mainly conducted below $100 \mathrm{~km}$ altitude so far.

However, some attempts have been made using MF radars to investigate the height region above $100 \mathrm{~km}$, where only powerful MST radars and IS radars can be used for wind measurements. Namboothiri et al. (1993, 1994) discussed

Copy right(C) The Society of Geomagnetism and Earth, Planetary and Space Sciences (SGEPSS); The Seismological Society of Japan; The Volcanological Society of Japan; The Geodetic Society of Japan; The Japanese Society for Planetary Sciences. the possibility of wind measurements up to $125 \mathrm{~km}$ by using partial reflection echoes during geomagnetically quiet nights. Another approach has been done using echoes from ionized meteor trails (Brown, 1976; Olsson-Steel and Elford, 1987; Meek and Manson, 1990; Steel and Elford, 1991). Meteor echo observations for wind measurement have been mainly performed with HF or VHF radio waves so far. The HF/VHF observations are, however, limited to below $110 \mathrm{~km}$ because of the very fast diffusion of ionized meteor trails at greater altitudes (Aso et al., 1979; Nakamura et al., 1991). On the other hand, MF radars which use lower radio frequency have a great advantage in detecting meteor echoes well above 110 $\mathrm{km}$. Meek and Manson (1990) showed the great potential of meteor wind measurement using an MF radar although the time resolution and height coverage were rather limited because of some instrumental restriction. Steel and Elford (1991) conducted MF meteor observations for the study of height distribution of meteor echoes which deeply related to meteor flux into the atmosphere. Olsson-Steel and Elford reported meteor echoes distributed up to $140 \mathrm{~km}$ altitude when using a $2 \mathrm{MHz}$ system.

In this paper we report meteor echo observations using Adelaide MF radar system $\left(35^{\circ} \mathrm{S}, 138^{\circ} \mathrm{E}\right)$. In the following sections we first describe the principles of meteor wind observation. The experimental setup for the MF radar observation is shown in Section 3. Meteor echo detection and processing procedures are presented in Section 4. Time and spatial distributions of meteor echoes are described in Section 5. Horizontal wind velocities are estimated in Section 6. 
Discussion and conclusions are presented in Section 7.

\section{Principles of Meteor Wind Observation}

When a meteoroid impinges on the earth's atmosphere, it interacts with neutral atmosphere and ablates meteor atoms, which have an initial velocity comparable to that of the meteoroid (about $11-73 \mathrm{~km} / \mathrm{s}$ ). Collisions between the ionized atoms and atmospheric molecules are frequently repeated to slow the ions down to the thermal velocities of the environment neutral atmosphere within less than a millisecond (McKinley, 1961). The trail has an initial radius, $r_{0}$, approximated by

$$
\log _{10} r_{0}=0.019 h-1.92+\log _{10}(V / 40)
$$

where $r_{0}$ is in meters, and $h$ and $V$ are altitude in $\mathrm{km}$ and impinging velocity in $\mathrm{km} / \mathrm{s}$, respectively (Baggaley, 1980, 1981; Thomas et al., 1988). When $V$ is $40 \mathrm{~km} / \mathrm{s}, r_{0}$ is 0.62 $\mathrm{m}$ at $90 \mathrm{~km}$ altitude, and is $1.5 \mathrm{~m}$ at $110 \mathrm{~km}$. The higher the trail lies, the larger the initial radius becomes because of fewer collisions. The meteor trail is further moved by wind motion of ambient neutral atmosphere.

Echoes can be received from meteor trails by using radio waves. The radio wave penetrates into meteor trails, and is scattered by each electron when the radio frequency is less than the plasma frequency of the ionized trail. Alternatively the radio wave is reflected on the surface by the trail when the plasma frequency is higher than the radio frequency. The former type is called "underdense echoes", and the latter "overdense echoes". An approximate boundary line density of these two types is given by $2.4 \cdot 10^{14} \pi^{3}\left(r_{0} / \lambda\right)^{2}(/ \mathrm{m})$, where $\lambda$ is the radio wavelength in meters (McKinley, 1961). Doppler frequency shift of an underdense echo gives information on wind velocity. On the other hand that of an overdense echo is affected by the motion of the trail surface which expands in the radial direction very rapidly, thus not used for wind measurement. We limit our interest only in underdense echoes in the rest of this paper.

When we consider an instantaneously formed infinitely long cylindrical meteor trail, the received echo power $P_{r}$ is calculated assuming Fresnel reflection (McKinley, 1961). The value of $P_{r}$ is obtained as

$$
\begin{aligned}
P_{r} & =\frac{P_{t} G^{2} \lambda^{3} \sigma_{e}}{128 \pi^{3} R^{3}} q_{e}^{2} \frac{c^{2}+s^{2}}{2} \\
& \simeq 2.5 \cdot 10^{-32} P_{r} G^{2}\left(\frac{\lambda}{R}\right)^{3}(W)
\end{aligned}
$$

where $P_{t}, G, R, \sigma_{e}$, and $q_{e}$ are transmitted power in watts, antenna gain, minimum range in meters from the radar to the trail, the scattering cross section of electron, and line electron density in the trail, respectively. It is noteworthy that the echo power has radio wavelength dependency. When the effective antenna area, proportional to $G \lambda^{2}$, is the same, the echo power is proportional to the wave length. In Fresnel reflection, most of the echo power is determined by the region, so called, "the first Fresnel zone", which is the portion around the perpendicular point to the radar. Its length is given as $\sqrt{2 \lambda R}$. When the range is $100 \mathrm{~km}$, the Fresnel zone is 5.5 $\mathrm{km}$ long for a $2 \mathrm{MHz}$ system.
After their formation meteor trails expand in the radial direction mainly due to ambipolar diffusion. The resulting destructive summation of scattered radio wave by each electron reduces the echo power as follows

$$
P_{r}(t)=P_{r}(0) \exp \left(-\frac{32 \pi^{2} D t}{\lambda^{2}}\right)
$$

where $P_{r}(t)$ is the echo power at time, $t$, after the trail formation, and $D$ is the ambipolar diffusion coefficient. As $D$ is inversely proportional to the atmospheric density, the scale height of $D$ is about $6-7 \mathrm{~km}$. Under some assumptions atmospheric temperature information can be obtained from $D$ and used for the study of atmospheric waves (Tsutsumi et al., 1994; Jones, 1995; Tsutsumi et al., 1996; Nakamura et al., 1997). The larger diffusion at the higher altitude shortens the echo duration, and limits VHF meteor radar studies below $110 \mathrm{~km}$ altitude. However, this equation shows that the duration becomes dramatically longer by using a radar with a lower radio frequency. For example the echo duration for an MF radar operated at $2 \mathrm{MHz}$ is 600 times as long as that for a $50 \mathrm{MHz}$ system.

Here we also discuss some issues and disadvantages in using low-frequency radars. One of the long-discussed issues on meteor trails is the effect of magnetic field on the motion of ionized meteor trails (e.g., Baggaley and Webb, 1980; Jones, 1991). Roughly above $95 \mathrm{~km}$, the motion of electrons becomes increasingly magnetically dominated due to fewer collisions with the neutral atmosphere. Jones (1991) theoretically discussed that the diffusion of meteor trails can be severely inhibited above $95 \mathrm{~km}$ altitude depending on the geometric condition of trails relative to the magnetic field. Although this does not affect the neutral wind measurements because the total motion of meteor trails are still determined by the collision of ions and the neutral atmosphere, the decay of underdense meteor trails may not be simply explained by ambipolar diffusion. Some experimental approaches have been done (Baggaley and Webb, 1980), but the effect has not been fully tested yet because of very few observations conducted above $100 \mathrm{~km}$ so far. Further, when we see greater altitudes than $110 \mathrm{~km}$, even the motion of ions becomes gradually geomagnetically dominated and the effects of electric field to the total motion of meteor trails, that is $\mathrm{E} \times \mathrm{B}$ drift, can arise. This effect could be more notable in the higher magnetic latitudes, where the magnetic field becomes stronger. This is essentially important for meteor echo study of neutral atmosphere motion and should be fully investigated. However, it is beyond the scope of the present study, and we do not discuss it further here.

A disadvantage of low frequency systems is its limited observation time. The highly ionized E layers in day time block the transmitted radio wave, and any meteor echoes above around $100 \mathrm{~km}$ can not be detected at middle frequencies. Olsson-Steel and Elford (1987) limited their meteor observation with the Buckland Park $2 \mathrm{MHz}$ system to 03-07 LT. They reported that after sunrise E-layer developed very rapidly and no observations were possible.

Namboothiri et al. (1993) discussed the possibility of conventional partial reflection measurements of an MF radar at altitudes greater than $100 \mathrm{~km}$ in Saskatoon $\left(52^{\circ} \mathrm{N}, 107^{\circ} \mathrm{W}\right)$. They reported that the group retardation of $2.2 \mathrm{MHz}$ radio 
Table 1. Observational parameters.

\begin{tabular}{ll}
\hline Operational frequency & $1.98 \mathrm{MHz}$ \\
Peak power & $50 \mathrm{~kW}$ \\
$\begin{array}{l}\text { Pulse repetition freq. } \\
\text { Transmitting antenna }\end{array}$ & $16 \mathrm{~Hz}$ \\
$\quad$ half power full width & about $10 \mathrm{deg}$. \\
beam directions & 4 dirs, Ze: $25^{\circ}, \mathrm{Az}: 0^{\circ}, 90^{\circ}, 180^{\circ}, 270^{\circ}$ \\
Reception & 5 receivers to construct an interferometer \\
receivers & 4 times \\
coherent integration & $70-148 \mathrm{~km}($ every $2 \mathrm{~km})$ \\
sampling range &
\end{tabular}

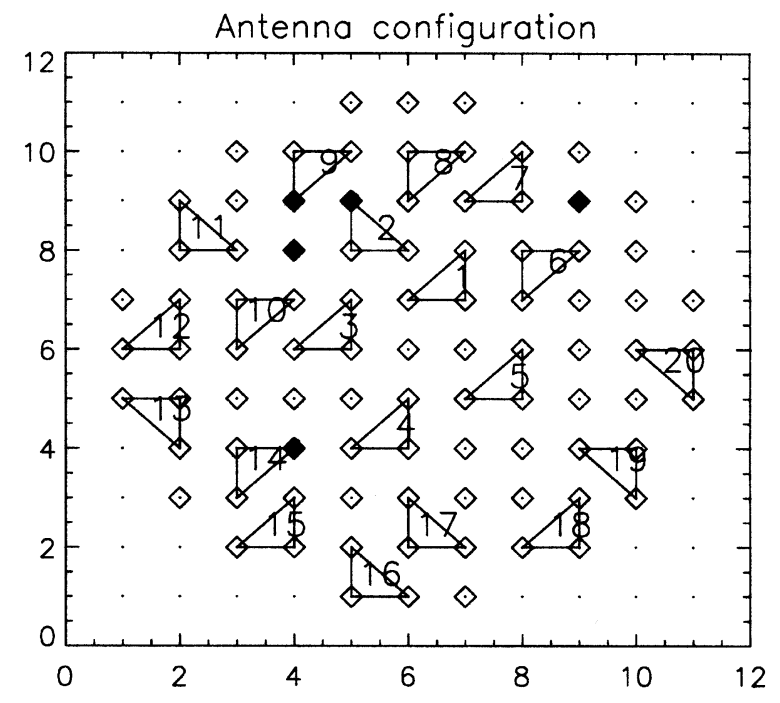

Fig. 1. Antenna configuration of the Buckland Park MF radar. Twenty groups of antennas, each of which consists of three dipole antennas, were used for transmission. Black symbols indicate the five antennas for reception.

wave at night was almost negligible. As the Buckland Park MF radar, which we used in the present study, is also located in the mid-latitude region, the group retardation is probably not a severe problem. However, this may not apply to the polar region, where the ionized particles precipitate, and complicated electro-magnetic phenomena take place.

\section{Experimental Setup}

Observation was conducted using the Buckland Park MF $\operatorname{radar}\left(35^{\circ} \mathrm{S}, 138^{\circ} \mathrm{E}\right)$ between 00:40-05:46 LT on October 22 , 1997. Observational parameters are shown in Table 1. The transmitted radio frequency and power were $1.98 \mathrm{MHz}$ and $50 \mathrm{~kW}$, respectively.

Figure 1 shows the antenna configuration of the observation. Sixty out of eighty-nine east-west aligned dipole antennas were used for transmission to form pencil beams with off-zenith angles of $25^{\circ}$. The beam directions were switched every time series, that is, every two minutes, in four direc-

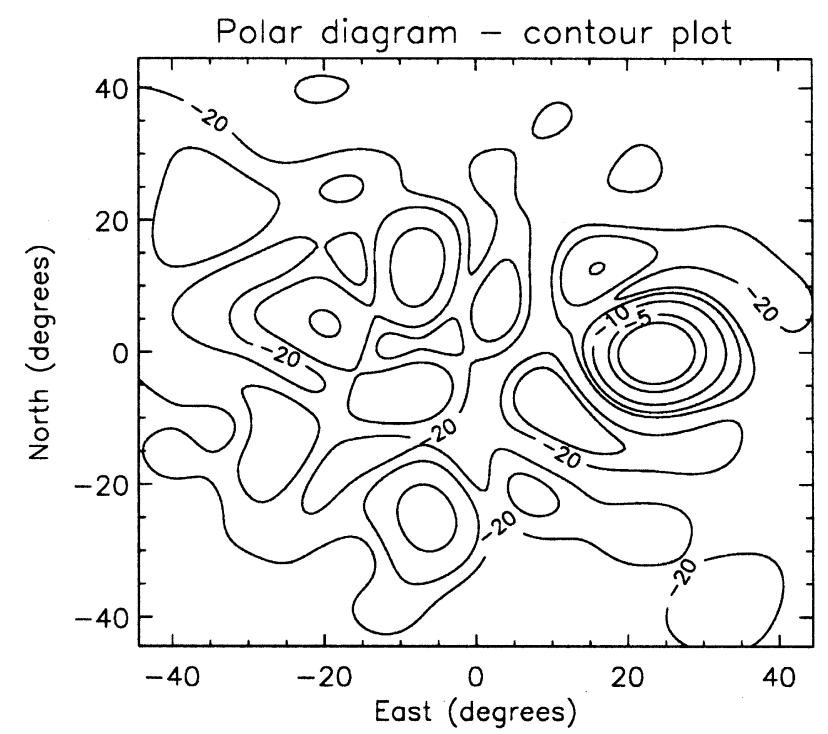

Fig. 2. A contour plot of transmitting antenna pattern for the eastward beam. Values are in $\mathrm{dB}$ relative to the maximum gain.

tions with azimuth angles of $0^{\circ}, 90^{\circ}, 180^{\circ}$ and $270^{\circ}$. The radiation pattern of the east beam is plotted in Fig. 2. Half power full width was about $10^{\circ}$. The first sidelobe level was about $-10 \mathrm{~dB}$ relative to the main lobe. The other beams had similar patterns to Fig. 2. Five dipole antennas indicated as black symbols in Fig. 1 composed a radio interferometer. The shortest and longest base lines were $91.4 \mathrm{~m}$ and $457 \mathrm{~m}$, respectively. As the shortest baseline is $0.60 \lambda$ and longer than $0.5 \lambda$, arrival angles of meteor echoes cannot be necessarily determined without ambiguities. Echoes at a zenith angle of larger than $56.4^{\circ}$ contaminate the first lobe of the interferometer. However, considering that more than $90 \%$ of underdense meteor echoes distribute at altitudes higher than $80 \mathrm{~km}$ (Nakamura et al., 1991), the ambiguities can be avoided by limiting the maximum sampling range. When we assume the lowest meteor to appear at $80 \mathrm{~km}$ altitude, meteor echoes which return at the zenith angles larger than $56.4^{\circ}$ are never sampled at the range shorter than $145 \mathrm{~km}$. We set the sampling range from 70 to $148 \mathrm{~km}$ in the present study. The 


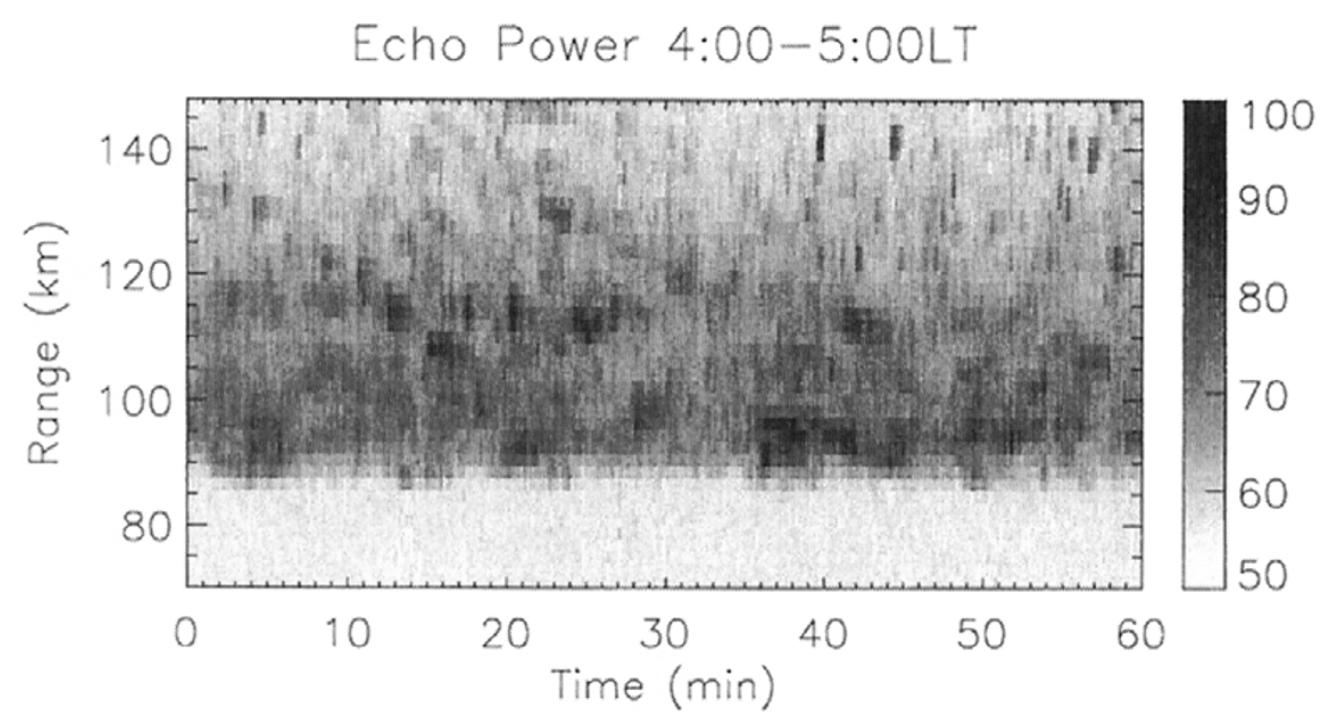

Fig. 3. A time-height plot of echo power in $\mathrm{dB}$ for the receiver 1 at 04:00-05:00 LT.

range resolution was $2 \mathrm{~km}$. In the real experiment, however, some ambiguities can exist because of some echoes below $80 \mathrm{~km}$. But as we are mainly interested in meteor echoes above $100 \mathrm{~km}$ in the present study, echoes at the lower altitudes, which have long durations and thus small diffusion coefficients, can be easily identified, and do not affect the following analyses.

In order to detect short duration meteors at high altitudes a pulse repetition frequency as high as possible is required. However, for a technical reason a pulse repetition frequency of $16 \mathrm{~Hz}$ was employed in the observation. The resulting limitation is discussed in Section 6. Received complex signals at every range were coherently integrated 4 times, then stored in time series with length of 380 points, that is, 95 seconds. Transmission was stopped for the following 25 seconds, then the same procedure was repeated. Thus, 30 time series a hour were recorded for every range bin. All the data was written to the hard disk. Real time meteor echo detection was not conducted.

It should be noted here that the observations happened to be conducted during a major meteor shower activity, the Orionids. Its possible effect on the number of detected echoes is discussed in Section 5.

\section{Echo Detection and Data Processing}

Figure 3 shows the time-range section of echo power of the receiver 1 observed at 4:00-5:00 LT. Note that the data gaps with the duration of 25 seconds are not plotted to avoid complicated outlook. Instead, each data of 95 seconds is expanded in a manner to fill the gaps, and mapped in the figure. The most conspicuous feature is the enhancement from 90 to $120 \mathrm{~km}$, which was due to reflection from $\mathrm{E}$ layer even during night time. Echo power below $80 \mathrm{~km}$ was very weak, and no notable characteristics are seen. Above 120 $\mathrm{km}$, however, strong enhancements, but with short durations of less than a minute, were often observed. An example of such echoes, observed at 05:34 LT, is presented in Fig. 4. A sudden increase and following exponential decrease of echo power with time is clearly seen. Phase values during the en- hancement of echo power indicates that the echo was Doppler frequency shifted. Phase difference between the receivers 1 and 2 is almost constant during the echo event. These are commonly observed features of underdense meteor echoes (e.g., Nakamura et al., 1991), and the many enhancements seen in Fig. 3 are reasonably identified as echoes from meteor trails.

We detected and processed meteor echoes in the following manner.

(1) We selected meteor echo candidates when power series of the receiver 1 exceeded a meteor echo model plotted as a black pattern in Fig. 4(a). Echoes with a peak signal-tonoise ratio (SNR) greater than $10 \mathrm{~dB}$ and a duration longer than 1.5 seconds were chosen. Because of the fairly long pulse width $(30 \mu \mathrm{sec})$ for meteor observations and also the over sampling, meteor echoes sometimes appeared at several adjacent range bins. To avoid multi-counting the same echo the range bin with the strongest echo power was selected. Note that the scatter from E layer was strong even during night time, especially at around $100 \mathrm{~km}$. Thus, in order to avoid contamination from ionospheric returns which happen to look like meteor echoes, we only searched the data at the range longer than $110 \mathrm{~km}$ in this study.

(2) Arrival directions of the detected candidates were estimated with the phase differences between the five receivers. Data of the three receivers forming the smallest triangle were first used to estimate rough arrival directions, then more accurate directions were determined by using the largest triangle. (3) The five complex series were coherently averaged after removing the phase differences. Theoretically the signal to noise ratio can be increased by $7 \mathrm{~dB}$. This is basically a post beam swinging technique, and unwanted signals are also suppressed.

(5) Underdense echoes were selected by searching the coherently integrated power series. Power series showing a sharp increase and then an exponential decrease with time were identified as underdense echoes and used in the following analyses. Ambipolar diffusion coefficient of each underdense echo was evaluated by least square fitting to the 
(a)

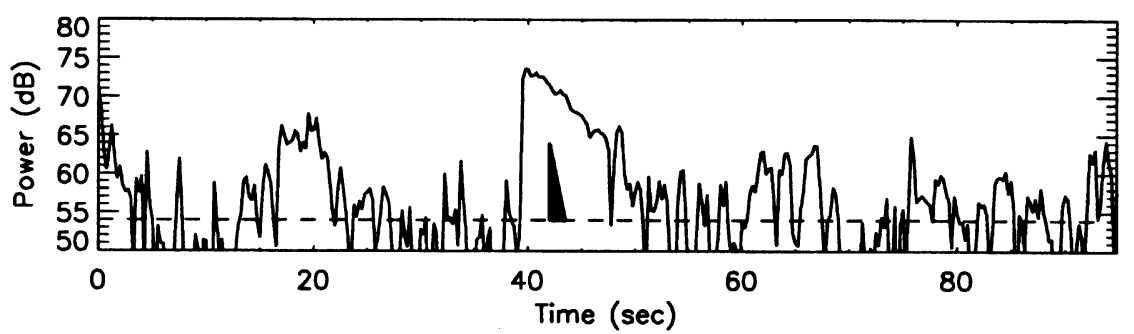

(b)

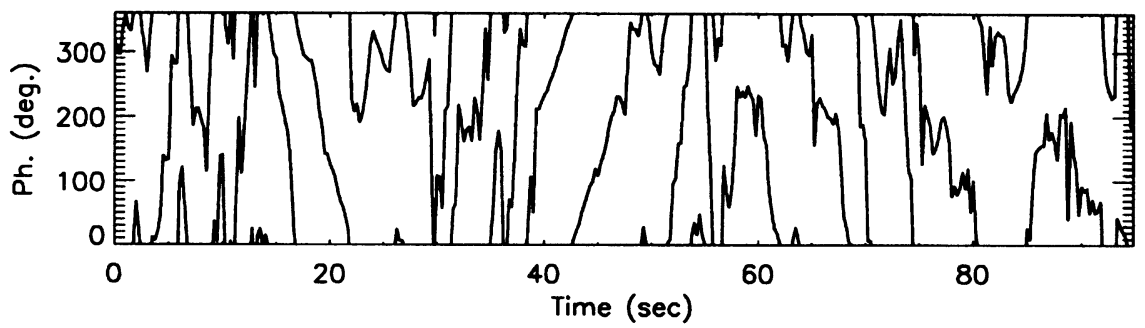

(c)

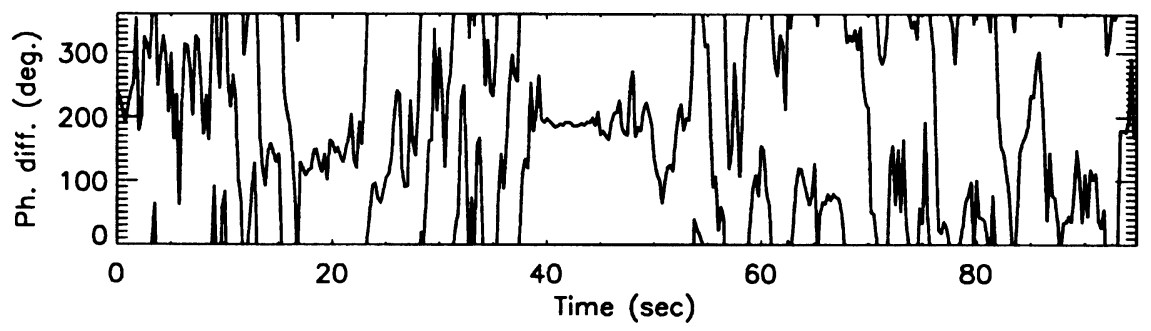

Fig. 4. Time series of (a) echo power and (b) phase received with the receiver 1 at 05:36 LT at the range of $136 \mathrm{~km}$. (c) Phase difference between the receivers 1 and 2.

power series.

(6) Finally the radial wind velocity was estimated by least square fitting to the coherently averaged phase series.

\section{Distributions of Underdense Meteor Echoes}

The total number of underdense meteor echoes obtained during 00:40-05:46 LT is 233. The hourly echo rate of them is shown in Fig. 5. The echo rate is from 40 to 60. As the observation was stopped at 5:46 LT, the real hourly rate during 5-6 LT is estimated to have been nearly 80 . A clear tendency of the rate increasing with time toward morning shows a good agreement with HF/VHF meteor radar studies. The range distribution of underdense echoes is plotted in Fig. 6. Although a broad peak is seen around $135 \mathrm{~km}$, Fig. 6 implies that many echoes could be observed at range longer than $148 \mathrm{~km}$.

The height distribution of underdense echoes is shown in Fig. 7. Echoes are detected from 80 to $120 \mathrm{~km}$. The mean and standard deviation are $104.4 \mathrm{~km}$ and $6.7 \mathrm{~km}$, respectively. The mean height is roughly $10 \mathrm{~km}$ higher than conventional VHF meteor radar studies (e.g., Olsson-Steel and Elford, 1987). Here we compare our results with those by Olsson-Steel and Elford (1987). They conducted meteor observations using the same radar as the present study, but with a different setup and echo processing algorithm. The mean height of the present study is almost exactly the same with theirs. However, their results show that echoes were distributed at least up to $140 \mathrm{~km}$, which is about $20 \mathrm{~km}$ higher

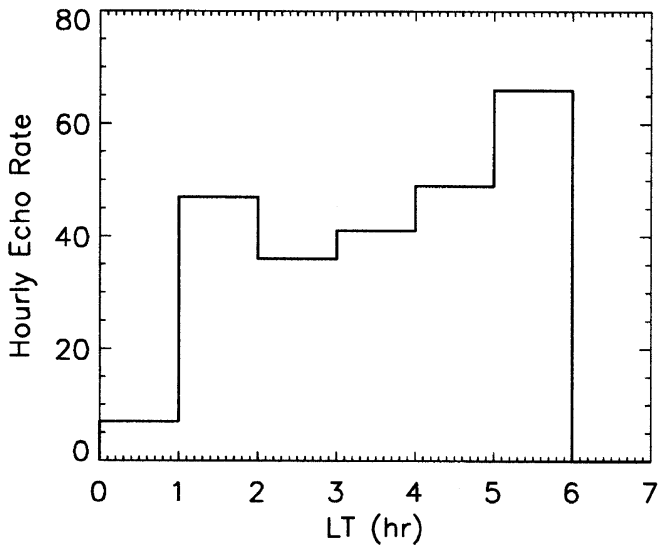

Fig. 5. Hourly echo rate of underdense echoes.

than our result. The difference arose probably because we chose only echoes showing exponential decay with a duration longer than $1.5 \mathrm{sec}$, and could not detected short-lived echoes while Olsson-Steel and Elford (1987) studied the height distribution itself, and investigated echoes with a much shorter duration. As for the distribution below $100 \mathrm{~km}$ the present study shows a rather abrupt drop in number of echoes, which is not the case in Olsson-Steel and Elford (1987), where a more gradual decrease down to about $70 \mathrm{~km}$ is reported. The difference also seems largely due to our preferential selection of echoes with an exponentially decrease in power. Echoes at lower altitudes have usually longer duration because of 


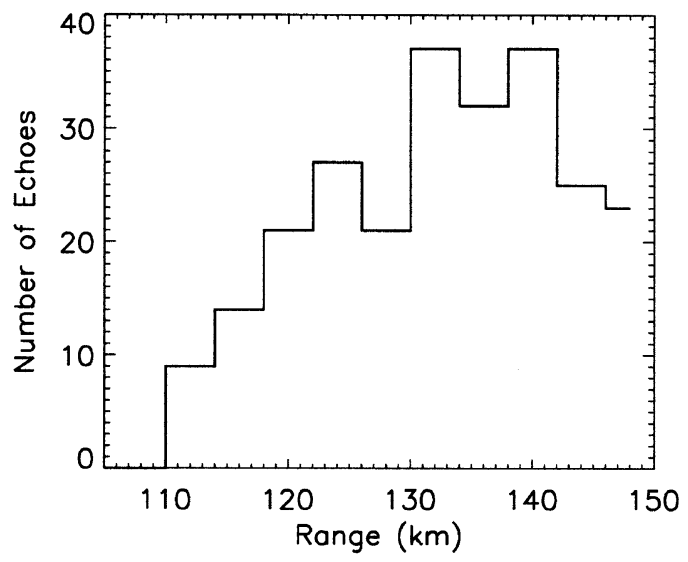

Fig. 6. Height distribution of underdense echoes. Mean height and standard deviation are $104.4 \mathrm{~km}$ and $6.7 \mathrm{~km}$, respectively.

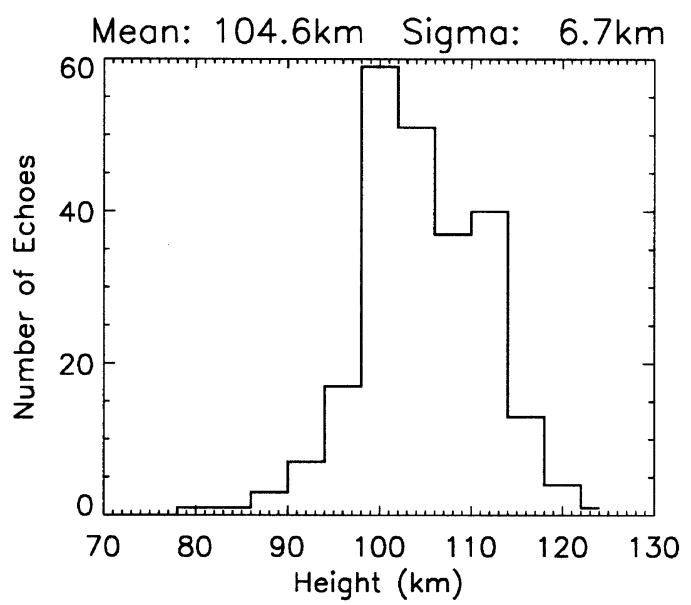

Fig. 7. Polar plot of angular distribution of underdense echoes. Symbols $\mathrm{N}, \mathrm{E}, \mathrm{S}$ and $\mathrm{W}$ indicate echoes detected while transmission was made with the north, east, south, west beams, respectively. The inner and outer circles correspond to the zenith angles of $25^{\circ}$ and $50^{\circ}$, respectively.

slower ambipolar diffusion. Long duration echoes quite often show distorted time variations and do not necessarily decrease exponentially with time, at least partly because of trail deformation by neutral wind shear (e.g., Jones and Read, 1972), thus are mostly discarded and do not used for further analyses. The duration of echoes with a clear exponential feature is mostly less than $20 \mathrm{sec}$ in this study. As longduration echoes may be useful if processed properly, it will be worth trying to improve echo detection algorithm in the future study. Another possible cause of the low echo rate below $100 \mathrm{~km}$ is the fact that the analysis is limited to echoes sampled at range of longer than $110 \mathrm{~km}$ as described in Section 4.

Angular distribution of underdense echoes is summarized in Fig. 8. It is clear that most of echoes arrived from west. Considering the fact that the Fresnel reflection is responsible for the meteor echo scattering mechanism, the direction of radiant point is perpendicular to echo arrival direction. Thus, most meteor bodies are thought to have approached the radar site from the east-side of the sky. This shows a reasonable

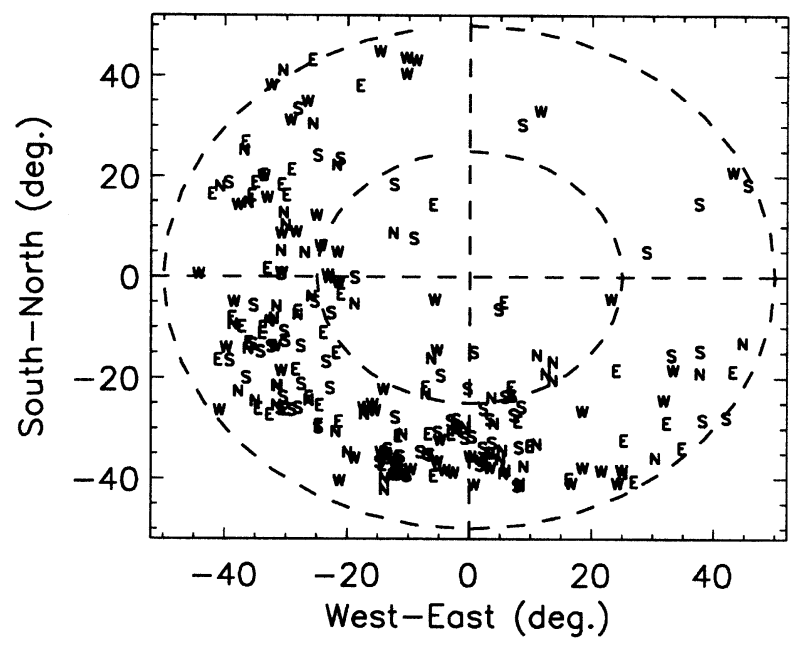

Fig. 8. Range distribution of underdense echoes. The minimum and maximum sampling ranges of $110 \mathrm{~km}$ and $148 \mathrm{~km}$ are shown with the dotted lines.

agreement with the fact that because of the earth's evolution around the sun more meteor bodies enter the atmosphere from the morning side of the earth, that is, the east side in the case of observations made early in the morning. Further, it is interesting that few underdense echoes were detected within main beams steered at $25^{\circ}$ zenith angles, and that almost all the other echoes arrived from greater zenith angles. Thus, a large amount of transmitted energy was not used to receive underdense meteor echoes.

Spatial distribution of underdense echoes in zenith angleheight section is shown in Fig. 9. The tendency of more echoes at greater zenith angles is clearly seen. The dotted line indicating the maximum sampling range of $148 \mathrm{~km}$ implies that many echoes are expected at greater ranges as described above.

A scatter diagram of ambipolar diffusion coefficients against height is shown in Fig. 10 together with a theoretical model profile by Thomas et al. (1988). In general the observed ambipolar diffusion coefficients increase exponentially with height. However, they show a much wider scatter than those observed with VHF systems (e.g., Tsutsumi et al., 1994). Below $105 \mathrm{~km}$ the values of ambipolar diffusion coefficients distribute around the model values. However, above that level the observation does not show a clear tendency while the model values increase exponentially with an almost unchanged slope from the lower altitude. The wide scatter in the observations may be attributed to the deformation of meteor trails by wind shear. Jones and Read (1972) studied the effect of wind shear gradients on underdense echoes. Their results suggest that the decay time of underdense echoes can be severely affected for systems operating on large wave lengths such as an MF radar. While it is almost negligible for VHF systems. Further, the featureless distribution above $105 \mathrm{~km}$ seems to be caused by the observation limit set by the fairly slow sampling rate of the present study. Since the duration of each echo should be more than $1.5 \mathrm{sec}$ to be regarded as a meteor echo candidate as described in Section 3, the observable largest diffusion coefficients for echoes with peak SNR of 10, 20 and $30 \mathrm{~dB}$ are 112, 223 


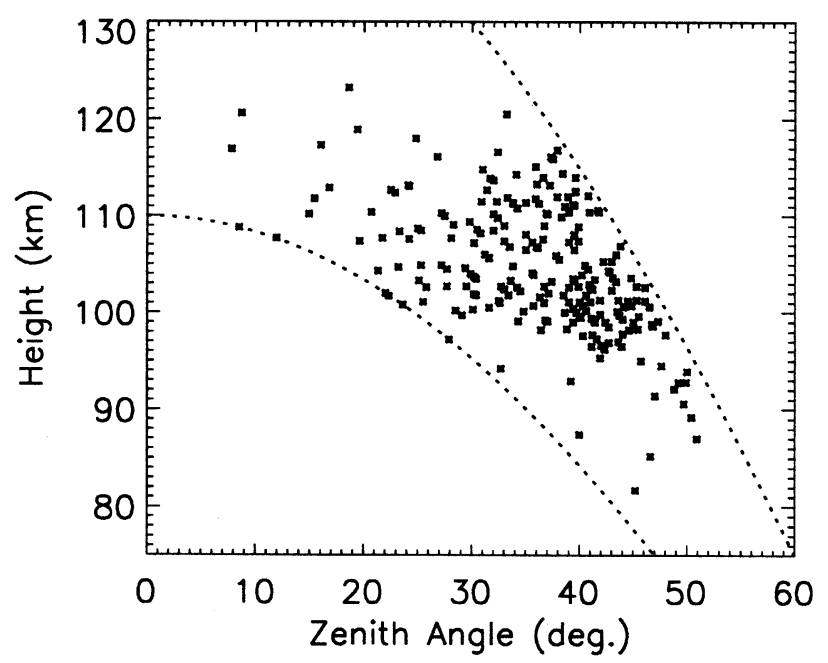

Fig. 9. Zenith-angle vs. height section of underdense echo distribution.

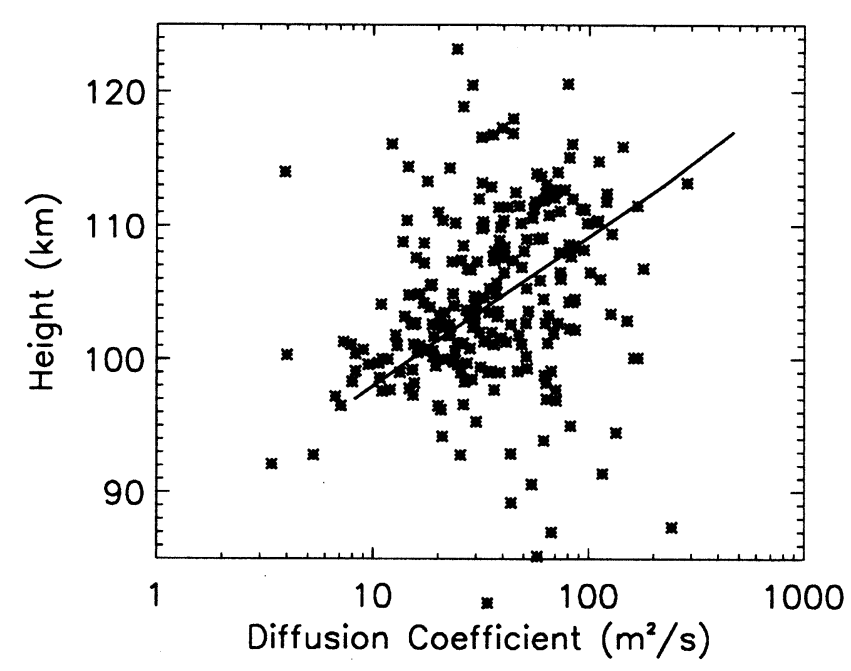

Fig. 10. Scatter plot of ambipolar diffusion coefficients estimated from decay constants of underdense echoes. Solid line shows the model profile by Thomas et al. (1988).

and $335 \mathrm{~m}^{2} / \mathrm{s}$, respectively. As most of detected echoes had peak SNR less than $20 \mathrm{~dB}$, the model profile infers that many echoes above $110 \mathrm{~km}$ still remain undetected. Note that the magnetic field effect to restrict trail diffusion may be also responsible for the small values of $D$ (e.g., Jones, 1991). But unfortunately we could not investigate the effect using the present data with a not fast enough sampling frequency.

Here we discuss the possible effect of meteor shower activity on the number of echoes. As described in Section 3 the observations happened to be done during the Orionids meteor shower. In order to estimate the effect we plotted the echo arrival angles on a celestial coordinate (not shown). Since an underdense echo is received from the direction perpendicular to the direction of the meteor radiant point, shower meteors, which have usually a single radiant, distribute around the big circle perpendicular to the radiant direction on the celestial sphere (e.g., Poole and Roux, 1989). The distribution of the present observations show that about $40 \%$ of the underdense echoes located around the big circle of the known radiant of the Orionids meteor shower. Provided all those echoes were from the shower meteors, the contribution of them to the total number of underdense echoes was at most $40 \%$. At least some part of those echoes, however, are quite possibly from non-shower meteors with different radiants, and received from the direction perpendicular to the Orionids radiant direction by chance. Thus, it can be said that the vast majority of the underdense echoes in the present study were from non-shower meteors.

Based on the echo distributions described in this section an improved experimental setup for the future study is discussed in Section 7.

\section{Wind Velocity Estimation}

We estimated wind velocity in each time-height bin with dimensions of 2 hours and $4 \mathrm{~km}$. As the vertical wind velocity is generally much smaller than the horizontal components, it was neglected in the wind estimation and only horizontal components were calculated. A horizontal wind vector was fitted by employing a least square method only when the number of echoes in each bin was more than eight. The bin was shifted by 1 hour or $2 \mathrm{~km}$, that is, a half size of the bin, and the calculation was repeated. The obtained bi-hourly wind velocities are summarized in Fig. 11, where the confidence interval of each estimation is also shown. Wind velocities were able to be estimated from $94 \mathrm{~km}$ to $114 \mathrm{~km}$. The upper limit of wind measurement is about $10 \mathrm{~km}$ higher than that of conventional VHF meteor radar observations, where the number of meteors detected above $100 \mathrm{~km}$ is usually not enough to estimate wind velocities. A wave-like motion is seen in the profiles, especially in the meridional component where a clear downward propagation of phase structure with time was observed. This is a typical feature of an upward energy propagating atmospheric wave. The vertical wavelength is estimated to be roughly $30 \mathrm{~km}$. This wavelength can suggest that the observed pattern may be related to atmospheric tides, which has been regularly observed at low to mid-latitude sites (e.g., Vincent et al., 1988), or otherwise a large scale inertial gravity wave.

In an attempt to deduce wind information continuously from the meteor height down to $80 \mathrm{~km}$, we estimated FCA winds at $80-100 \mathrm{~km}$ using data from three of the five receiving antennas which formed a right-angled triangle with the minimum spacing of $91.4 \mathrm{~m}$. Although an FCA method is usually applied to data obtained with a vertically pointed beam, it was tried to the present data, which was observed with only oblique beams. The way of analysis is basically the same with the conventional FCA. Liu et al. (1991) studied the oblique method, and showed this technique can be used to estimate various kinematic parameters of wind fields such as divergence in addition to conventionally measured parameters. It should be noted, however, that it is still not an established method, and that some uncertainties in wind estimation exist.

A continuous wave structure evolving with time is clearly observed over a $35 \mathrm{~km}$ height layer $(80 \mathrm{~km}$ to $114 \mathrm{~km})$. When we pay attention to the most dominant wave component with a vertical wavelength of about $30 \mathrm{~km}$, the zonal component seems to lead the meridional component by $5-10 \mathrm{~km}$, that 

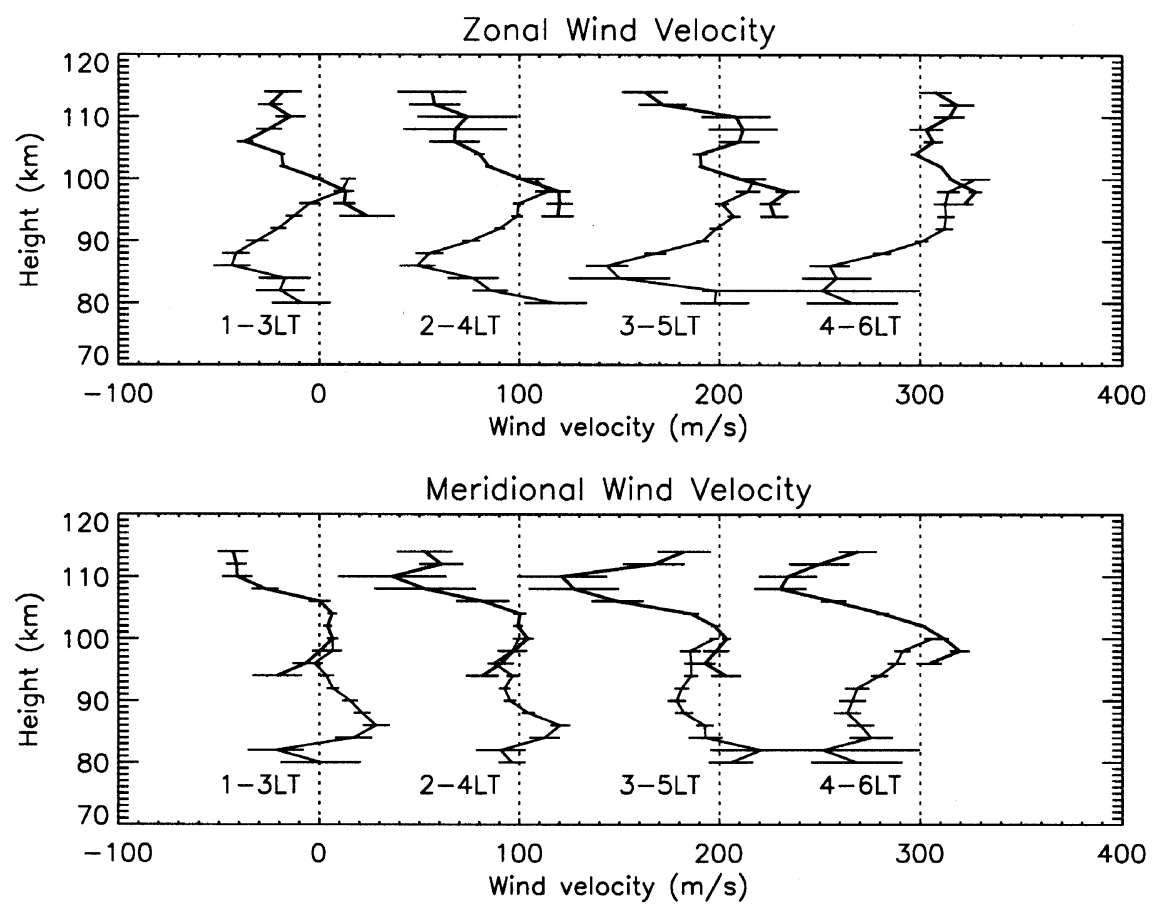

Fig. 11. Bi-hourly wind profiles for (a) zonal and (b) meridional components. Thick and thin lines are winds estimated using meteor echoes and an FCA method, respectively. Confidential intervals are shown with horizontal bars.

is, about a quarter of the wavelength. This indicates the wind field rotated counterclockwise, which is a characteristic of atmospheric waves in the southern hemisphere. Overall agreement between the meteor and FCA winds around 100 $\mathrm{km}$ is good. However, some disagreements are also evident. Sometimes meteor winds were larger, and vice versa. The largest difference is about $30 \mathrm{~m} / \mathrm{s}$. The discrepancy seems to be largely caused by the poorly estimated meteor wind near the lower boundary of echo distribution.

The difference may be also partly attributed to the experimental setup which was not optimal for FCA analysis; the transmitting beam was not steered vertically but toward the off-zenith angle of $25^{\circ}$, the receiving antenna configuration was not equilateral triangle, and the antenna spacing was not ideal (refer on possible effects caused by these configurations to e.g., Holdsworth (1999)). Biases in MF radar wind measurements have been recently discussed through comparative wind measurements using multiple techniques (e.g., Burrage et al., 1996). Precise comparison between MF meteor and FCA winds should be performed. However, it should be waited until observations with an optimal experimental setup are conducted.

\section{Discussion and Conclusions}

We conducted meteor echo observations with Buckland MF radar $\left(35^{\circ} \mathrm{S}, 138^{\circ} \mathrm{E}\right)$ at 00:40-05:45 LT on October 22, 1997. Despite the limited observation period the results were very promising for MF meteor study. In total, 233 underdense echoes were detected with a mean height and standard deviation of $104.4 \mathrm{~km}$ and $6.7 \mathrm{~km}$, respectively. The mean height is about $10 \mathrm{~km}$ higher than that of the conventional VHF meteor observations. Note that the observations were conducted during a major meteor shower activity. However, most of the observed underdense echoes are judged to be from non-shower meteors, thus observations under no shower activity will also give enough number of echoes. Bi-hourly wind profiles with a height resolution of $4 \mathrm{~km}$ were obtained from $94 \mathrm{~km}$ to $114 \mathrm{~km}$. The profiles exhibited a wave structure showing a phase progression with time, which is a typical feature of atmospheric waves. Further, combined with simultaneously observed FCA winds, wind profiles were continuously estimated down to $80 \mathrm{~km}$. The height coverage was about $35 \mathrm{~km}$.

These results are quite encouraging. However, as OlssonSteel and Elford (1987) reported, MF meteor observations have a potential of detecting meteor echoes up to $140 \mathrm{~km}$. In fact the observational parameters of the present study were found not optimal for MF meteor study. Here we discuss an improved setup for the future study together with the possibility of applying this technique to conventional MF radars. (1) Sampling frequency

The pulse repetition frequency (PRF) was $16 \mathrm{~Hz}$, and the practical frequency became $4 \mathrm{~Hz}$ after coherent integration of 4 times. This would be the major factor which restricted the detection of short-lived echoes, thus limited the maximum echo height to $120 \mathrm{~km}$. Estimated ambipolar diffusion coefficients in Fig. 10 also seemed to be biased to small values above $105 \mathrm{~km}$. Considering that the scale height of the molecular diffusion is about $6 \mathrm{~km}$, echoes at $140 \mathrm{~km}$ may be detected by using a sampling frequency about 30 times higher than the present study if the same echo detection algorithm described in Section 3 is used. A high sampling frequency also enables us the study of impinging velocity of meteor echoes into the atmosphere, from the time evolution of phase pattern during the trail formation, which is further related to the study of the solar system (e.g., Cervera et al., 
1997).

(2) Sampling range

The maximum sampling range was set to be $148 \mathrm{~km}$. However, Fig. 6 suggests many meteor echoes at larger ranges. The maximum sampling range was set to be $148 \mathrm{~km}$ to minimize arrival angle ambiguities of echoes. However, Fig. 6 suggests that many meteor echoes existed at greater ranges. As only a small portion of echoes detected at longer ranges will have arrival angle ambiguities actually, most other echoes can be used for wind estimation. Therefore, the maximum range should be extended. In the case of a radar system with an equivalent minimum antenna spacing less than 0.5 $\lambda$, there is no arrival angle ambiguity, thus no upper limit of sampling range.

(3) Beam pattern

Narrow transmitting beams with off-vertical angles of $25^{\circ}$ were found ineffective for meteor study as seen in Fig. 8. A broad beam pattern as reported by Nakamura et al. (1991) could work well for MF meteor study. Nakamura et al. (1991) showed that 1.6 times larger number of echoes were detected by using a doughnut-shaped transmitting antenna pattern with its peak at $30^{\circ}$ zenith angle in a meteor study using the MU radar. This also suggests that the broad beam of conventional MF radars can gather meteor echoes pretty efficiently. The conventional systems are equipped with three or four receiving antennas. Operated under interferometry mode, many of the MF systems can be used as meteor radars. As the maximum antenna spacing of conventional MF systems is less than one wavelength and much shorter than that of the present study, the accuracy of the echo arrival angle would be worse. Additional antennas to expand the maximum spacing may be necessary.

(4) Improved antenna configuration

Antenna configuration of the present study was not ideal for the FCA. Observations with an equilateral configuration with a proper spacing should be conducted for a precise comparison between meteor and FCA wind measurements. (5) On-line meteor echo detection

All the meteors were off-line processed in this study. We are developing an on-line echo detection software. It could be applied to conventional MF radars in the future.

By these improvements the number of echoes will be at least doubled, and hourly (or even better) wind profiles could be obtained. These data can be further used for the study of mean winds and also atmospheric waves like inertial gravity waves above mesopause. There are some restrictions which should be noted as well. The observations can be performed only at night when the ionospheric return is weak. The effects of geomagnetic field and electric field have not been experimentally studied sufficiently. Hence a careful treatment of MF meteor data should be done. However, there are very few techniques to measure the region above $100 \mathrm{~km}$. MF radar observations of meteor echoes are expected to greatly contribute to the study of this region.

Acknowledgments. The Buckland Park MF radar is supported by ARC grants, A69031462 and A69231890.

\section{References}

Aso, T., T. Tsuda, and S. Kato, Meteor radar observations at Kyoto Univer- sity, J. Atmos. Terr. Phys., 41, 517-525, 1979.

Baggaley, W. J., Multi frequency studies of radio-meteor train diffusion, Bull. Astron. Inst. Czechosl., 31, 305-308, 1980.

Baggaley, W. J., Single wavelength measurements of the initial radii of radio meteor ionization columns, Bull. Astron. Inst. Czechosl., 32, 345, 1981.

Baggaley, W. J. and T. H. Webb, The geomagnetic control of the diffusion of meteoric ionization, Planet. Space Sci., 28, 997-1001, 1980.

Brown, N., Radio echoes from meteor trains at a radio frequency of 1.98 MHz, J. Atmos. Terr. Phys., 38, 83-87, 1976.

Burrage, M. D., W. R. Skinner, D. A. Gell, P. B. Hays, A. R. Marshall, D. A. Ortland, A. H. Manson, S. J. Franke, D. C. Fritts, P. Hoffman, C. McLandress, R. Niciejewski, F. J. Schmidlin, G. G. Shepherd, W. Singer, T. Tsuda, and R. A. Vincent, Validation of mesosphere and lower thermosphere winds from the high resolution Doppler imager on UARS, J. Geophys. Res., 101, 10,365-10,392, 1996.

Cervera, M. A., W. G. Elford, and D. I. Steel, A new method for the measurement of meteor speeds: The pre-t0 phase technique, Radio Sci., 32, 805-816, 1997.

Holdsworth, D. A., Influence of instrumental effects upon the full correlation analysis, Radio Sci., 34, 643, 1999.

Jones, J. and B. A. Read, The effect of wind shear gradients on underdense radio meteor decay time, Ca. J. Phys., 50, 1277-1281, 1972.

Jones, W., Theory of diffusion of meteor trains in the geomagnetic field, Planet. Space Sci., 39, 1283-1288, 1991.

Jones, W., The decay of radar echoes from meteors with particular reference to their use in the determination of temperature fluctuations near the mesopause, Ann. Geophysicae, 13, 1104-1106, 1995.

Liu, C. H., J. Röttger, G. Dester, S. J. Franke, and C.-J. Pan, The oblique spaced antenna method for measuring the atmospheric wind field, J. Atmos. Ocean. Technol., 6, 26-35, 1991.

McKinley, D. W. R., Meteor Science and Engineering, 309 pp., McGrawHill, New York, 1961.

Meek, C. E. and A. H. Manson, MF radar interferometer measurements of meteor trail motions, Radio Sci., 25, 649-655, 1990.

Nakamura, T., T. Tsuda, M. Tsutsumi, K. Kita, T. Uehara, S. Kato, and S. Fukao, Meteor wind observations with the MU radar, Radio Sci., 26, 857-869, 1991.

Nakamura, T., T. Tsuda, S. Fukao, H. Takahashi, P. P. Batista, R. A. Buriti, M. Tsutsumi, M. Ishii, K. Igarashi, H. Fukunishi, Y. Yamada, A. Nomura, T. D. Kawahara, K. Kobayashi, C. Nagasawa, M. Abo, and M. J. Taylor, Studies of the MLT region using the MU radar and simultaneous observations with $\mathrm{OH}$ spectrometer and other optical instruments, Adv. Space Res., 19, 643-652, 1997.

Namboothiri, S. P., A. H. Manson, and C. E. Meek, E region real heights and their implications for MF radar-derived wind and tidal climatologies, Radio Sci., 28, 187-202, 1993.

Namboothiri, S. P., A. H. Manson, and C. E. Meek, Extension of MF radar tidal measurements to E-region heights $(95-125 \mathrm{~km})$ : Saskatoon $\left(52^{\circ} \mathrm{N}\right.$, $\left.107^{\circ} \mathrm{W}\right)$, Canada, Ann. Geophysicae, 12, 333-341, 1994.

Olsson-Steel, D. and W. G. Elford, The height distribution of radio meteors: observations at 2 MHz, J. Atmos. Terr. Phys., 49, 243-258, 1987.

Poole, L. M. G. and T. R. Roux, Meteor radiant mapping with an all-sky radar, Mon. Not. R. Astr. Sci., 236, 645-652, 1989.

Steel, D. I. and W. G. Elford, The height distribution of radio meteors: comparison of observations at different frequencies on the basis of standard echo theory, J. Atmos. Terr. Phys., 53, 409-417, 1991.

Thomas, R. M., P. S. Whitham, and W. G. Elford, Response of high frequency radar to meteor backscatter, J. Atmos. Terr. Phys., 50, 703-724, 1988.

Tsutsumi, M., T. Tsuda, T. Nakamura, and S. Fukao, Temperature fluctuations near the mesopause inferred from meteor observations with the middle and upper atmosphere radar, Radio Sci., 29, 599-610, 1994.

Tsutsumi, M., T. Tsuda, T. Nakamura, and S. Fukao, Wind Velocity and Temperature Fluctuations due to a Two-day Wave Observed with Radio Meteor Echoes, J. Geophys. Res., 101, 9425-9432, 1996.

Vincent, R. A., MF/HF radar measurements of the dynamics of the mesopause region-A review, J. Atmos. Terr. Phys., 46, 961-974, 1984.

Vincent, R. A., T. Tsuda, and S. Kato, A comparative study of mesospheric solar tides observed at Adelaide and Kyoto, J. Geophys. Res., 93, 699$708,1988$.

M. Tsutsumi (e-mail: tutumi@uap.nipr.ac.jp), D. Holdsworth, T. Nakamura, and I. Reid 